\title{
Geología y estructura de las sierras de Guanajuato y Codornices, Mesa Central, México
}

\author{
Geology and structure of Guanajuato and Codornices ranges, Mesa Central, Mexico
}

Paola del Río Varela ${ }^{1,2, *}$, Ángel Francisco Nieto-Samaniego ${ }^{1}$, Susana A. Alaniz-Álvarez ${ }^{1}$, Edgar Ángeles-Moreno ${ }^{1,3}$, Felipe de Jesús Escalona-Alcázar ${ }^{2,}$, Alexis del Pilar-Martínez ${ }^{1,3}$

${ }^{1}$ Universidad Nacional Autónoma de México, Campus Juriquilla, Centro de Geociencias, Boulevard Juriquilla No. 3001, Juriquilla, 76230, Querétaro, México.

${ }^{2}$ Universidad Autónoma de Zacatecas, Unidad Académica de Ciencias de la Tierra, Calzada de la Universidad No. 108, Fracc. Progreso, 98058, Zacatecas, México.

${ }^{3}$ Posgrado en Ciencias de la Tierra, Centro de Geociencias, Universidad Nacional Autónoma de México, Campus Juriquilla, 76230, Querétaro, México.

* Autor para correspondencia: (P. del Río

Varela)paodelivo@@gmail.com

\section{Cómo citar este artículo:}

del Río, P., Nieto-Samaniego A., AlanizÁlvarez S., Ángeles-Moreno E., EscalonaAlcázar F., del Pilar-Martínez, A., 2020, Geología y estructura de las sierras de Guanajuato y Codornices, Mesa Central, México: Boletín de la Sociedad Geológica Mexicana, 72 (1), A071019. http://dx.doi. org/10.18268/BSGM2020v72nla071019

Manuscrito recibido: Julio 31, 2018

Manuscrito corregido: Septiembre 29, 2018

Manuscrito aceptado: Octubre 6, 2018

La revisión por pares es responsabilidad de la

Universidad Nacional Autónoma de México.

Este es un artículo Open Access bajo la licencia CC BY-NCSA (https://creativecommons.org/licenses/by-nc-sa/4.0/)

\section{RESUMEN}

Para contribuir al conocimiento sobre la tectónica cenozoica del centro de México se consideró estudiar la estructura e historia del levantamiento de las sierras de Guanajuato y Codornices, ya que constituyen un elemento tectónico donde se expone a las rocas de Jurásico-Cretácico y que se encuentra elevado hasta a $700 \mathrm{~m}$ por encima de la cuenca El Bajío. El área de estudio es el límite entre la Mesa Central y la parte centro-septentrional de la Faja Volcánica Transmexicana, ubicándose en un lugar clave para estudiar la tectónica cenozoica del centro de México. En el área hay dos entidades orográficas: (1) la Sierra de Guanajuato y (2) la Sierra de Codornices. En conjunto, ambas sierras conforman el bloque levantado de una semifosa tectónica de edad Oligoceno-Eoceno, en la cual se ha desarrollado la cuenca de El Bajío. Compilando la cartografía geológica actual del área de estudio, se reconocieron 6 conjuntos litológicos que registran los eventos tectónicos principales: rocas Jurásico-Cretácicas, conglomerados eocénicos, rocas volcánicas y plutónicas del Ypresiano, rocas volcánicas del Rupeliano, rocas del Chattiano y rocas del Mioceno. Con esta información elaboramos $27 \mathrm{sec}-$ ciones geológicas, configurando un modelo integral de la geometría y distribución de unidades estratigráficas y fallas cenozoicas. Las rocas volcánicas de Ypresiano se encuentran únicamente en el sector NW del área de estudio como remanentes de una cubierta más extensa ya erosionada. Las rocas volcánicas de Rupeliano presentan una diferencia en su distribución: a lo largo del margen SW del área de estudio se depositaron rocas piroclásticas, mientras que a lo largo del frente NE se emplazaron grandes volúmenes de rocas volcánicas efusivas. La actividad de las fallas normales durante el Oligoceno y Mioceno migró del núcleo de la Sierra de Guanajuato hacia la cuenca E Bajío, imprimiéndole al frente SW de las sierras de Guanajuato y Codornices una forma escalonada con la parte más hundida hacia la cuenca El Bajío. En contraste, a todo lo largo del margen NE del área de estudio las fallas normales son escasas y no se aprecia bien definido un frente montañoso escarpado, sino una inclinación suave hacia el NE, imprimiéndole a toda el área la forma de un bloque basculado. Las sierras de Guanajuato y Codornices experimentaron tres grandes fases de levantamiento-exhumación: la primera en el Ypresiano-Bartoniano, la segunda en el Oligoceno y la tercera en el Mioceno, adquiriendo su configuración actual en esta última. El levantamiento relativo con respecto a la cuenca El Bajío fue siempre mayor en la Sierra de Guanajuato y menor en la Sierra de Codornices.

Palabras clave: levantamiento-exhumación, tectónica cenozoica, Falla del Bajío, Mesa Gentral de México, Sierra de Guanajuato.

\section{ABSTRACT}

To increase the knowledge of tectonic evolution of central Mexico during the Cenozoic, it was considered to study the structure and uplift history of the Guanajuato and Codornices ranges. They form a tectonic element, elevated up to $700 \mathrm{~m}$ relative to the El Bajio basin, and where the furassic-Cretaceous basement is exposed. The study area is the limit between the Mesa Central and the central-northern part of the Transmexican Volcanic Belt. It is located in a key place to study the Cenozoic tectonics of central Mexico. There are two important orographic entities in the study area: (1) the Sierra de Guanajuato and (2) the Sierra de Codornices. Together they form the raised block of an Oligocene-Eocene half-graben, which bounds the El Bajio basin. By compiling the geological maps of the study area, we recognized six lithologic groups: Jurassic-Cretaceous rocks, Eocene conglomerates, Mpresian volcanic and plutonic rocks, Rupelian volcanic rocks, Chattian rocks and Miocene rocks. With this information, we elaborated 27 geological sections, configuring a complete model of the geometry and distribution of stratigraphic units and Cenozoic faults. The Eocene volcanic rocks are only found in the $\mathcal{N W}$ sector of the study area as remnants of a more extensive and eroded cover. The Rupelian volcanic activity has a difference in its distribution: along the SW margin of the study area, pyroclastic rocks were deposited, while throughout the $\mathcal{N} E$ front large volumes of effusive volcanic rocks were emplaced. The Oligocene and Miocene activity of the normal faults occurred in successive phases forming the stepped configuration to the SW margin of the Sierras of Guanajuato and Codornices due to the migration of the active zones towards the basin. In contrast, normal faults are scarce and a steep mountainous front is not well defined along the entire $N E$ front of the study area. In this part, the slopes gently dip towards the NE giving the whole area the shape of a tilted block. The Sierra de Guanajuato and the Sierra de Codornices experienced three major phases of uplift-exhumation: the first in the early-middle Eocene, the second in the Oligocene and the third in the Miocene, when acquired the current configuration. The relative rise with respect to El Bajio basin was always higher in the Sierra de Guanajuato and lower in the Sierra de Codornices.

Keywords: upload-exhumation, Cenozoic tectonics, El Bajío fault, Mesa Central, Guanajuato range. 


\section{Introducción}

El área de estudio constituye el límite meridional de la Mesa Central, separándola de la parte centro-septentrional de la Faja Volcánica Transmexicana (FVTM) (Figura 1A). Desde un punto de vista geomorfológico se trata de una serranía limitada hacia el sur y suroeste por una cuenca que se conoce como "Cuenca de El Bajío" (Botero-Santa et al., 2015), y al norte y noreste por una planicie elevada con montañas aisladas denominada Mesa Central (MC) (Nieto-Samaniego et al., 2005) (Figura 1B). Durante el Cenozoico, en la Mesa Central tuvo lugar una deformación extensional con una fase eocénica, el acmé entre los 30 y 27 $\mathrm{Ma}$, y fases de menor magnitud en el Mioceno, entre 24 y 11 Ma (Nieto-Samaniego et al., 2005).

La deformación fue de tipo tridimensional y fue acomodada principalmente por sistemas de fallas con orientaciones NE-SW y NW-SE (Nieto-Samaniego et al., 1999, 2005). Otros autores han documentado actividad de fallas en la MC consistente con las fases descritas: Tristán-González (1986) y
Orozco-Esquivel et al. (2002) documentaron que el desarrollo del Graben Villa de Reyes (GVR) (Figura 2A) ocurrió entre los 32 y $29 \mathrm{Ma}$; Botero-Santa et al. (2015) describen pulsos de actividad de la Falla del Bajío durante el Eoceno, Oligoceno y Mioceno; y Alaniz-Álvarez et al. (2001) documentaron, para la zona de Querétaro-Celaya, que las fallas N-S, NW-SE y NE-SW tuvieron actividad simultánea en eventos ocurridos en el Oligoceno y Mioceno.

En el área de estudio hay dos entidades orográficas: (1) la Sierra de Guanajuato (SG) es una serranía de forma alargada con dirección NW-SE, que se extiende por aproximadamente $100 \mathrm{~km}$ de largo y $35 \mathrm{~km}$ de ancho desde la región Comanja de Corona, Jalisco, hasta el Graben de La Sauceda; y (2) la Sierra de Codornices (SG), que se extiende desde el graben de La Sauceda hasta Comonfort, mide aproximadamente $45 \mathrm{~km}$ en dirección NW y 40 km en dirección NE (Figura 1B). En conjunto, ambas sierras conforman el bloque levantado de una semifosa tectónica de edad Eoceno-Oligoceno, que limita a la cuenca de El Bajío (Botero-Santa et al., 2015).
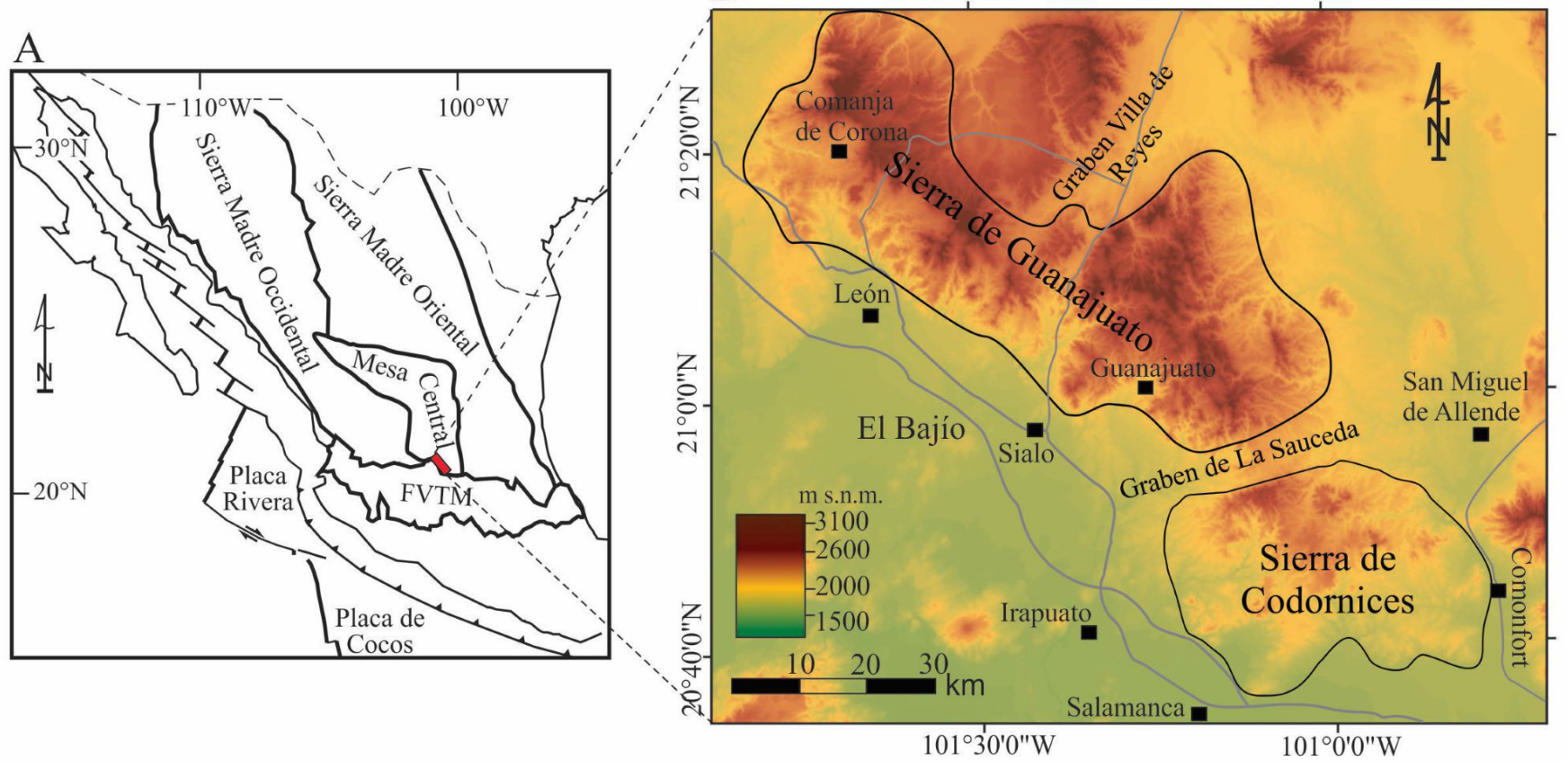

Figura 1 (A) Ubicación del área de estudio relativa a las provincias fisiográficas adyacentes. FVTM: Faja Volcánica Transmexicana. (B) Modelo digital de elevación del Instituto Nacional de Estadística y Geografía (INEGI, 2015) indicando la ubicación del área de estudio. Las líneas en gris son las carreteras principales. 
Hay numerosos trabajos que abordan la cartografía geológica del área de estudio desde hace más de un siglo (e. g. Botsford, 1909; Wandke y Martínez, 1928; Edwards, 1955; Echegoyén-Sánchez et al., 1970; Martínez-Reyes, 1992), pero hasta tiempos recientes se ha logrado el refinamiento de la estratigrafía cenozoica, por medio de nuevos mapas geológicos y de un buen número de fechamientos isotópicos (Nieto-Samaniego et al., 1996; Aranda-Gómez y McDowell, 1998; Cerca-Martínez et al., 2000; Nieto-Samaniego et al., 2005, Nieto-Samaniego et al., 2012; Nieto-Samaniego et al., 2015; Botero-Santa et al., 2015; Ángeles-Moreno et al., 2017). Gracias a esta información, se tiene por primera vez un conjunto de datos que abarcan casi en su totalidad la estratigrafía y las fallas cenozoicas de ambas sierras. Tomando ventaja de ello, compilamos un mapa geológico de toda el área y elaboramos 27 secciones geológicas. Con esta información presentamos aquí un modelo integral de la geometría y distribución de unidades estratigráficas y fallas cenozoicas de este elemento tectónico del centro de México.

\section{Metodología}

El elemento orográfico formado por las sierras de Guanajuato y Codornices es segmentado por dos fosas transversales denominadas Graben Villa de Reyes y Graben de La Sauceda (Figura 2A). Para nuestro análisis subsecuente, consideraremos tres sectores, (sector NW, sector centro y sector SE) que corresponden a cada una de las partes que dichos grábenes transversales forman. Los sectores considerados tienen características morfológicas, estructurales y estratigráficas distintas que expondremos en los apartados siguientes.

Para la construcción de las secciones se utilizó el mapa geológico que se muestra en la Figura 2A, el cual se elaboró integrando mapas de la zona de estudio publicados (Echegoyén-Sánchez et al., 1970; Martínez-Reyes, 1992; Alvarado-Méndez et al., 1997a, 1997b; Pérez-Flores et al., 1999; Cerca-Martínez et al., 2000; Nieto-Samaniego, 1990;
Nieto-Samaniego et al., 2012; Nieto-Samaniego et al., 2015; Botero-Santa et al., 2015; Ángeles-Moreno et al., 2017). Los datos estructurales y estratigráficos principales se obtuvieron de Nieto-Samaniego (1990), Ramos-Leal et al. (2007a), Nieto-Samaniego et al. (2012), Botero-Santa et al. (2015), Nieto-Samaniego et al. (2015) y Ángeles-Moreno et al. (2017). Los perfiles topográficos se construyeron mediante un sistema de información geográfica (QGIS, 2015), a partir del Continuo de Elevaciones Mexicano 3.0 del Instituto Nacional de Estadística y Geografía INEGI (INEGI, 2015).

Los perfiles presentaban pequeños errores debidos a la interpolación de las cotas, por lo que se procedió a corregirlos de forma manual, comparando los perfiles con las cartas topográficas 1:50000 del Instituto Nacional de Estadística y Geografia (INEGI) edición 2015: F14-C31 a C34 y F14-C41 a C44. La dirección preferencial de las secciones es NE-SW viendo al NW con longitudes que varían entre $30 \mathrm{~km}$ y $60 \mathrm{~km}$. Se utilizó una exageración vertical de 5:1 y los echados de fallas y capas fueron corregidos tanto por echados aparentes como por exageración vertical. Las secciones se elaboraron manualmente sobre papel y posteriormente se digitalizaron.

\section{Geología del área de estudio}

La Sierra de Guanajuato y Sierra de Codornices se ubican dentro de dos provincias geológicas, la Sierra Madre Occidental (SMOc) (Faja Ignimbrítica Mexicana en la nomenclatura de Ortega-Gutiérrez et al., 1992) y la FVTM. La SMOc se extiende en dirección NW-SE, está formada por una pila de ignimbritas y domos mayormente de composición riolítica. Estas rocas volcánicas fueron emplazadas durante dos pulsos magmáticos principales, uno de edad Oligoceno temprano (32-28 Ma) y otro del límite Oligoceno tardío-Mioceno temprano (24-20 Ma, Ferrari et al., 2005). La FVTM es una provincia volcánica que se extiende en dirección E-W en el centro de México, de composición principalmente básica, cuyas edades van del Mioceno 
A

$101^{\circ} 50^{\prime} 00^{\prime \prime} \mathrm{W}-101^{\circ} 20^{\prime} 00^{\prime \prime} \mathrm{W}$

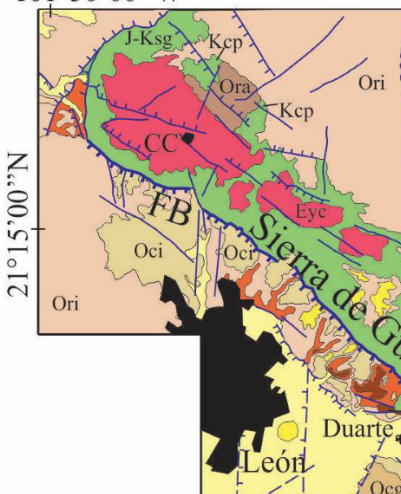

\section{B $\quad$ SECTOR}
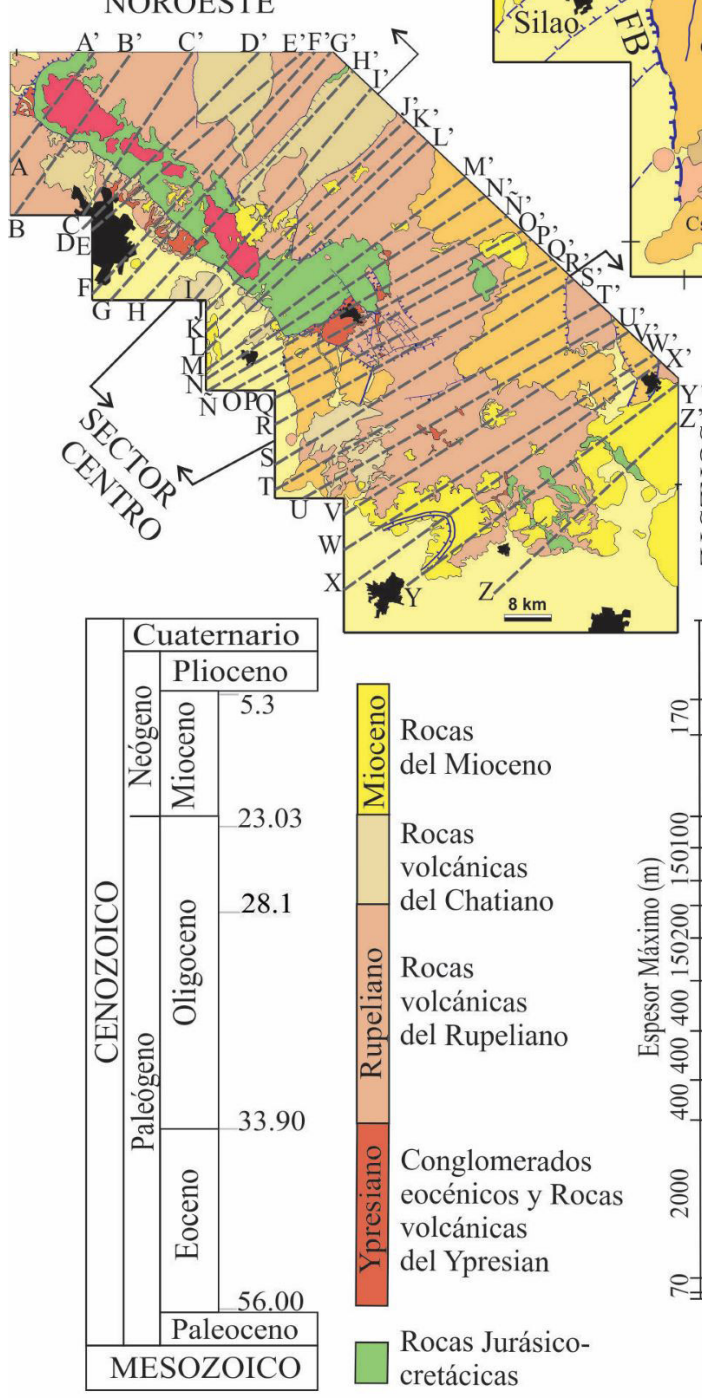

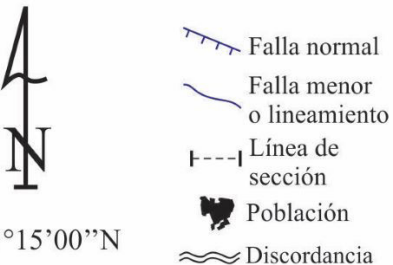

$101^{\circ} 00^{\prime} 00^{\prime \prime} \mathrm{W}$

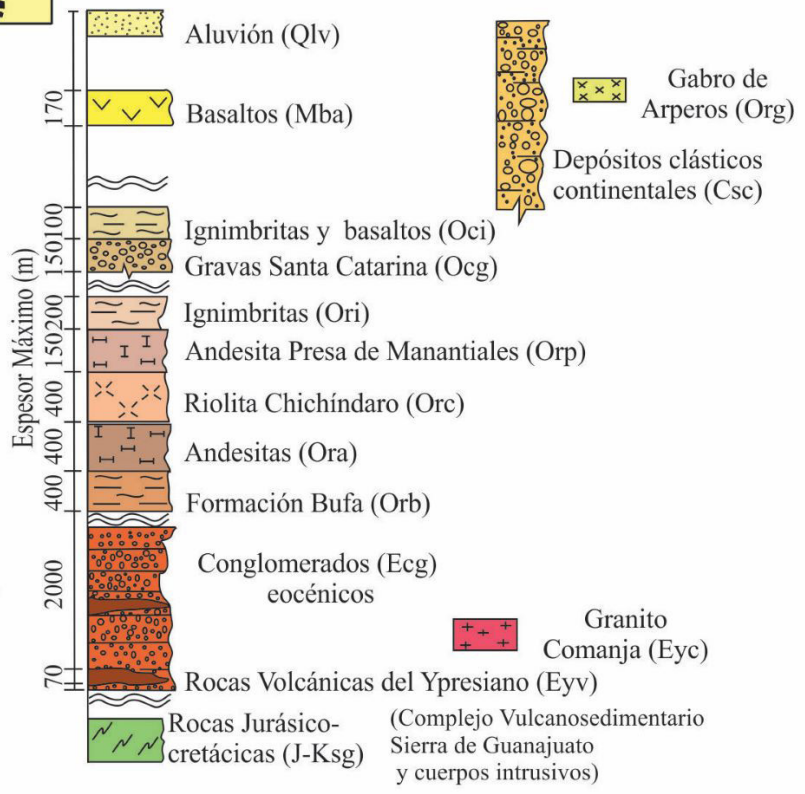

Figura 2 (A) Mapa geológico del área de estudio. G: Guanajuato, DMG: Distrito Minero de Guanajuato, CC: Comanja de Corona, CO: Caldera La Ordeña, MO: Mesa del Obispo, ET: El Terrero, LS: La Sauceda, FB: Sistema Falla del Bajío, FDMG: Fallas del Distrito Minero de Guanajuato, FSMA: Falla de San Miguel de Allende, GVR: Graben Villa de Reyes, GS: Graben de La Sauceda, ML: Mineral de La Luz. (B) Mapa geológico por conjuntos litológicos donde se muestra la ubicación de las secciones. 
medio hasta el Holoceno. Estas rocas se han interpretado como un arco volcánico asociado a la subducción de las placas de Cocos y Rivera (e.g. Ferrari et al., 2005).

\subsection{ESTRATIGRAFÍA}

Las unidades estratigráficas que afloran en el área de estudio, y que han sido descritas en la literatura, son de dos tipos: mesozoicas marinas y cenozoicas continentales. En este trabajo se agrupan de la manera siguiente: rocas del Jurásico-Cretácico, conglomerados eocénicos, rocas volcánicas y plutónicas del Ypresiano, rocas volcánicas del Rupeliano, rocas del Chattiano y rocas del Mioceno (Figura 2B).

\subsubsection{ROCAS JURÁSICO-CRETÁCICAS (J-Ksg EN LA FIGURA 2)}

En esta unidad se incluyen a las rocas volcánicas y clásticas Jurásico-cretácicas, descritas por Martínez-Reyes (1992) como Complejo Volcanosedimentario Sierra de Guanajuato, junto con los cuerpos intrusivos de edad mesozoica que afloran en la SG. En la Figura 2A, todo ese conjunto de rocas está como una sola unidad. Los afloramientos de rocas del Jurásico-Cretácico se encuentran principalmente en el núcleo de la SG, y existe un afloramiento de menor extensión en San Antón de las Minas. En la Sierra de Codornices los afloramientos son más aislados y están ubicados entre San Miguel de Allende y Santa Cruz de Juventino Rosas (Figura 2A). Martínez-Reyes (1992) y Ortiz-Hernández et al. (2003) describen a las rocas marinas de esta unidad como una sucesión tipo flysch que alterna con flujos basálticos y lavas almohadilladas, con metamorfismo de bajo grado. En la SC fueron descritas como arenisca, lutita y pedernal intercalados con rocas volcánicas y numerosas capas de material piroclástico, con un metamorfismo de bajo grado. En el Distrito Minero Guanajuato (DMG) se puede observar el contacto superior discordante de las rocas del Jurásico-Cretácico con los conglomerados Duarte y Guanajuato, mientras que en otras zonas del área de estudio las rocas del Jurásico-Cretácico yacen bajo las del Rupeliano, o del Mioceno. Las rocas del Jurásico-Cretácico han sido fechadas por varios autores, mostrando un intervalo de edades que va desde 157 Ma hasta $112 \mathrm{Ma}$ (Ortíz-Hernández et al., 1990; Ruiz-González, 2015; Martini et al., 2011).

\subsubsection{CONGLOMERADOS EOCÉNICOS (Ecg EN LA FIGURA 2)}

Con este nombre se agrupan: el Conglomerado Duarte, el Conglomerado Guanajuato y otros conglomerados que afloran de manera dispersa en las sierras de Guanajuato y Codornices; esos afloramientos aparecen en los mapas, pero no han sido estudiados con detalle, yacen bajo las rocas volcánicas del Rupeliano. Echegoyén-Sánchez et al. (1970) asignan el nombre de Conglomerado Guanajuato a una sucesión de conglomerados y areniscas continentales que afloran en los alrededores de la ciudad de Guanajuato. Martínez-Reyes (1992) denomina Conglomerado Duarte a un conjunto de rocas clásticas continentales de estratificación masiva, expuestas al norte del poblado Duarte. Los afloramientos de los conglomerados se encuentran principalmente en el DMG, al noroeste de Duarte y al oeste de Comanja de Corona (Figura 2A). En la $\mathrm{SC}$ los afloramientos principales de estas rocas se encuentran al sureste de La Sauceda y al norte de Juventino Rosas (Figura 2A).

El espesor máximo del Conglomerado Duarte es de 1700 m en las cercanías de Duarte (Miranda-Avilés et al., 2016) y de $1000 \mathrm{~m}$ al norte de León (Ramos-Leal et al., 2007a), mientras que el espesor del Conglomerado Guanajuato es de $1400 \mathrm{~m}$ en el DMG (Gross, 1975) (Figura 2A).

Los conglomerados eocénicos descansan en discordancia angular sobre las rocas del Jurásico-Cretácico y son cubiertos por las rocas volcánicas del Rupeliano. Se han reportado rocas volcánicas intercaladas en estos conglomerados, cuyas edades van de los ca. $52 \mathrm{Ma}$ (Olmos-Moya, 2016) a los $c a$. 49 Ma (Aranda-Gómez y McDowell, 1998), por lo que su alcance estratigráfico abarca la mayor parte del Ypresiano. 


\subsubsection{ROCAS VOLCÁNICAS Y PLUTÓNICAS DEL YPRESIANO}

Granito Comanja (Eyc en Figura 2A). Echegoyén-Sánchez et al. (1975) nombraron Granito Comanja a un cuerpo granítico que se extiende desde Comanja de Corona hasta Mineral de la Luz (Figura 2A). El granito se presenta de forma alargada con dirección preferencial NW-SE. Los afloramientos más grandes se encuentran en los alrededores del poblado de Comanja de Corona y al NW de Arperos (Figura 2A). El Granito Comanja está conformado por cuerpos irregulares y diques, su composición varía de granito de biotita a granodiorita, contiene cuarzo $+\mathrm{K}$-feldespato+plagioclasa $>$ biotita, minerales accesorios como zircón, apatito y minerales opacos. El granito contiene brechas y vetas hidrotermales de espesor y orientación variada, ricas en turmalina y cuarzo (Ángeles-Moreno et al., 2017).

El Granito Comanja intrusiona las rocas del Jurásico-Cretácico y lo cubren rocas volcánicas del Oligoceno. Ángeles-Moreno et al. (2017) reportaron que su emplazamiento inició a los $51 \pm 0.3 \mathrm{Ma}$ cuando se emplaza el cuerpo principal y culminó a los 49.5 $\pm 0.8 \mathrm{Ma}$, cuando se emplazan los últimos diques (edades U-Pb, LA-ICPMS en zircón, promedio ponderado).

Rocas volcánicas del Ypresiano (Eyv en Figura 2A). Las rocas volcánicas del Ypresiano se encuentran intercaladas en el Conglomerado Duarte e incluyen rocas con tres litologías distintas que afloran al norte del poblado de Duarte (Figura 2A), que aquí denominamos informalmente: "sill félsico", "riolita La Laborcita" e "ignimbrita Palo Blanco". El sill es un cuerpo aproximadamente tabular de composición granítica, compuesto de fenocristales de cuarzo, feldespato potásico y plagioclasa; su edad es de $52.16 \pm 0.20 \mathrm{Ma}(\mathrm{U}-\mathrm{Pb}$, LA-ICPMS en zircón, promedio ponderado; Olmos-Moya, 2016). La riolita La Laborcita está formada por derrames de riolita con estructura bandeada de flujo y textura que va de afanítica a porfídica, con fenocristales de cuarzo, feldespato potásico y plagioclasa; tiene aproximadamente $70 \mathrm{~m}$ de espesor y una edad de $51.86 \pm 0.46 \mathrm{Ma}$
(U-Pb, LA-ICPMS en zircón, promedio ponderado; Olmos-Moya, 2016). La ignimbrita Palo Blanco se presenta como un depósito piroclástico de composición riolítica, en capas subhorizontales. Hacia la base no presenta capas y tiene matriz de ceniza y líticos; sobre ese depósito hay un paquete de ignimbritas soldadas con estructuras de fimme, que contiene fenocristales de cuarzo, sanidino, plagioclasa y minerales opacos; su edad fue determinada en 48.82 $\pm 0.97 \mathrm{Ma}$ (U-Pb, LA-ICPMS en zircón, promedio ponderado; Ruiz-González, 2015).

\subsubsection{ROCAS VOLCÁNICAS DEL RUPELIANO}

Formación Bufa (Orb en Figura 2A). Debemos aclarar que omitimos intencionalmente aquí a la Formación Losero, pues es muy delgada y puede considerarse la base de la Formación Bufa. Echegoyén-Sánchez et al. (1970) propusieron el nombre de Riolita Bufa; sin embargo, otros autores usan el nombre de Formación Bufa (Alvarado-Méndez et al., 1997a; Davis et al., 2009). Sus afloramientos se encuentran únicamente en el DMG (Figura 2A). Nieto-Samaniego et al. (2015) reportan que la Formación Bufa está compuesta por depósitos piroclásticos con al menos tres facies principales: la parte basal es ignimbrita soldada de colores rosa a beige y tiene estructuras tipo fiamme; la parte intermedia es de colores marrón a rosa con fragmentos líticos angulares a subangulares y con fenocristales de cuarzo, sanidino, plagioclasa y biotita; la parte superior no se observa en todos los afloramientos, está formada por pómez y ceniza, contiene fragmentos líticos marrón, el tamaño de las partículas varía de ceniza fina a gruesa. La Formación Bufa sobreyace de manera concordante al Conglomerado Guanajuato y subyace a las andesitas del Rupeliano. Nieto-Samaniego et al. (2015) estimaron un espesor de $\sim 400 \mathrm{~m}$, medido en un afloramiento al este del DMG y esos mismos autores documentan una edad de $33.53 \pm 0.48 \mathrm{Ma}$ (Ar-Ar, en feldespato potásico, edad de meseta).

Andesitas (Ora en Figura 2A). Aquí se incluyen la andesita El Gigante-Bernalejo, Formación El Cedro y Formación Calderones, todas ellas 
de edad Rupeliano (Martínez-Reyes, 1992; Botero-Santa et al., 2015; Nieto-Samaniego et al., 2015). A excepción de la Formación Calderones, consisten principalmente de lava andesítica de color gris y textura porfídica, definida por un ensamble de fenocristales de plagioclasa en una matriz afanítica (e. g. Quintero-Legorreta, 1992; Botero-Santa et al., 2015). La Formación Calderones aflora en el Distrito Minero de Guanajuato y consiste principalmente en rocas piroclásticas de composición andesítica (Nieto-Samaniego et al., 2015). Sus afloramientos se encuentran al norte de la SG, al norte de Mineral de la Luz, en el DMG y en la SC (Figura 2A). En el DMG, las andesitas subyacen a la Riolita Chichíndaro y sobreyacen discordantemente a la Formación Bufa. En el sector norte de la SG se encuentra yaciendo discordantemente sobre las rocas del Jurásico-Cretácico y en la Sierra de Codornices aparece yaciendo bajo ignimbritas del Rupeliano. En el DMG se le ha estimado un espesor máximo de 400 m (Nieto-Samaniego et al., 2015).

Riolita Chichíndaro (Orc en Figura 2A). Echegoyén-Sánchez et al. (1970) introdujo el nombre Riolita Chichíndaro tomándolo del cerro Chichíndaro que se localiza en el DMG. Nieto-Samaniego et al. (2015) describen a la Riolita Chichíndaro como domos, derrames de lava y toba, cuyas fuentes de emisión son los cuellos volcánicos de los domos, y que cubren gran parte de la porción sur de la Mesa Central. En el área de estudio se ubican al NE de la Sierra de Guanajuato y al norte de la Sierra de Codornices (Figura 2A). Nieto-Samaniego et al. (2015) documentan que la Riolita Chichíndaro localmente está asociada a brechas y vitrófidos, y las lavas contienen fenocristales de cuarzo+sanidino>>oligoclasa. La Riolita Chichíndaro descansa de manera discordante sobre las rocas del Jurásico-Cretácico, sobe el Conglomerado Guanajuato o la Formación Bufa; su contacto superior es con ignimbritas del Rupeliano y basaltos del Mioceno. Nieto-Samaniego et al. (2015) estimaron para la Riolita Chichíndaro un espesor mínimo de 200 m y máximo 400 m en la zona del DMG y obtuvieron una edad de $30.36 \pm 0.40 \mathrm{Ma}(\mathrm{U} / \mathrm{Pb}$ LA-ICPMS en zircones, promedio ponderado).

Andesita Presa de Manantiales (Orp Figura 2A). Nieto-Samaniego (1990) nombró Andesita Presa de Manantiales a la unidad que aflora al este de la localidad El Terrero. Sus afloramientos están ubicados de manera aislada en la parte sur del área de estudio, y otros más al NW de la caldera La Ordeña (Figura 2A). La Andesita Presa de Manantiales está formada de lavas andesíticas, las cuales tienen fenocristales de plagioclasa (labradorita) y piroxeno en una matriz de plagioclasa y piroxeno. Al NW de la caldera La Ordeña aflora a manera de derrames basálticos formando mesetas (Nieto-Samaniego et al., 2012). La Andesita Presa de Manantiales sobreyace a la Riolita Chichíndaro y a las rocas del Jurásico-Cretácico, y subyace a las rocas del Mioceno. Nieto-Samaniego et al. (2012) estimaron que la Andesita Presa de Manantiales supera los 100 m de espesor y restringieron su edad al Oligoceno con base a su posición estratigráfica.

Ignimbrias del Rupeliano Ori en Figura 2A). Aquí se incluyen la Ignimbrita Cuatralba (Quintero-Legorreta 1992; Botero-Santa et al., 2015), ignimbrita El Carrizo, ignimbrita El Salto (Nieto-Samaniego et al., 2012) e ignimbrita Cañada La Virgen (Nieto-Samaniego et al., 1996; Cerca-Martínez et al., 2000). Los afloramientos de las rocas volcánicas del Rupeliano se encuentran en la parte NW de la SG, al NE de la Sierra de Codornices, y hay afloramientos más pequeños al norte de la caldera La Ordeña (Figura 2A). Para la parte NW de la Sierra de Guanajuato, Botero-Santa et al. (2015) documentaron que la Ignimbrita Cuatralba se encuentra fuertemente basculada, y describen que contiene fragmentos líticos de arenisca, cristales de sanidino y pómez. Esos mismos autores obtuvieron una edad de

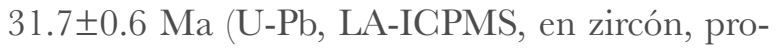
medio ponderado). Para la parte NE de la Sierra de Codornices, Alaniz-Álvarez et al. (2001) describieron la ignimbrita Cañada La Virgen como un 
depósito piroclástico de composición riolítica que presenta diferentes grados de piroconsolidación, pero que más comúnmente se la observa poco soldada y con depósitos piroclásticos y vitrófidos intercalados. Estos mismos autores le estimaron un espesor máximo de $200 \mathrm{~m}$, pero comentan que comúnmente no supera los $100 \mathrm{~m}$. Nieto-Samaniego et al. (1996) obtuvieron una edad de 28.6 $\pm 0.7 \mathrm{Ma}$ (K-Ar en sanidino).

$\mathrm{Al}$ norte de la caldera La Ordeña Nieto-Samaniego et al. (2012) reportaron la ignimbrita El Salto, la cual está compuesta de sanidino $>>$ cuarzo+ferromagnesianos+plagioclasas, estimándole un espesor de $60 \mathrm{~m}$ y obtuvieron una edad de 28.0 $1.1 \mathrm{Ma}$ (K-Ar en sanidino) para esta unidad.

La ignimbrita El Carrizo también fue reportada por Nieto-Samaniego et al. (2012). Esos autores la describen compuesta por plagioclasa sódica>cuarzo+sanidino y le estimaron un espesor de 60 m.

\subsubsection{ROGAS DEL CHATTIANO}

Depósitos clásticos continentales (Gsc Figura 2A). Esta unidad consiste en una sucesión de depósitos de areniscas y conglomerados no consolidados, o con mala consolidación, que se encuentran en la parte NE del área de estudio. Nieto-Samaniego et al. (2005) reportaron que estas rocas se afloran ampliamente en la Mesa Central; otros autores hacen referencia a ella como Gravas El Capulín y Conglomerado Xoconoxtle (Nieto-Samaniego et al., 1996; Nieto-Samaniego et al., 2012).

Gravas Santa Catarina (Ocg Figura 2A). Esta unidad fue descrita por Nieto-Samaniego (1992) dando el nombre de gravas Santa Catarina a las arenas y gravas continentales que yacen concordantemente sobre la Andesita Presa de Manantiales. Nieto-Samaniego et al. (2012) utilizaron el término conglomerado Santa Catarina para referirse a la misma unidad. Algunos afloramientos se encuentran al sur de La Sauceda, mientras que otros afloramientos están localizados al norte del poblado de Duarte (Figura 2A). Nieto-Samaniego (1990) documentó que esta unidad tiene mayor proporción de arena con intercalaciones de grava. Los clastos de grava en su mayoría son de composición riolítica y en menor proporción de andesita. El espesor de las gravas Santa Catarina varía notablemente, desde unas decenas de metros, hasta $150 \mathrm{~m}$ en la localidad de El Terrero. Nieto-Samaniego (1990) le asigna una edad del Oligoceno tardío dada su posición estratigráfica.

Ignimbritas y basaltos (Oci en Figura 2A). Aquí se incluyen ignimbritas y basaltos del Chattiano. Nieto-Samaniego (1990) reportó la ignimbrita San Nicolás y Botero-Santa et al. (2015) reportaron la Ignimbrita La Media Luna. Nieto-Samaniego et al. (2012) describieron a la ignimbrita San Nicolás en los alrededores de la caldera La Ordeña como flujos piroclásticos con distintos grados de soldamiento y desvitrificación, con fenocristales de sanidino $>>$ cuarzo+plagioclasa. La Ignimbrita San Nicolás cubre a la Riolita Chichíndaro, a la Andesita Presa de Manantiales y a las gravas Santa Catarina, aunque lo más común es encontrarla descansando directamente con las ignimbritas del Rupeliano. En la parte SE del área de estudio puede alcanzar $25 \mathrm{~m}$ de espesor. La ignimbrita San Nicolás fue fechada por Nieto-Samaniego et al. (1996) asignándole una edad de 24.8 $\pm 0.6 \mathrm{Ma}$ (K-Ar en sanidino).

Botero-Santa et al. (2015) reportaron la Ignimbrita La Media Luna, la cual se localiza en el frente SW de la SG. Esta ignimbrita está dispuesta en capas horizontales con espesores métricos, contiene pómez, cuarzo y abundante sanidino, se observan estructuras tipo fiamme de hasta $5 \mathrm{~cm}$ de longitud. La Ignimbrita La Media Luna se encuentra en discordancia angular sobre la Ignimbrita Cuatralba; los mismos autores fecharon esta unidad en 22.95 $\pm 0.15 \mathrm{Ma}$ (U-Pb, LA-ICPMS en zircón, promedio ponderado). Quintero-Legorreta (1992) y Martínez-Reyes (1992) definieron el Basalto Dos Aguas, para designar los basaltos del volcán Dos Aguas, localizado en León; los derrames de ese volcán se encuentran en el alto de la Falla del Bajío y aparecen intercalados con escoria volcánica que contiene augita y olivino (Botero-Santa et al., 2015). 


\subsubsection{ROCAS DEL MIOCENO}

Gabro de Arperos (Org en Figura 2A). El Gabro de Arperos es una roca hipabisal que aflora en el poblado de Arperos (Figura 2A), compuesta por plagioclasas de composición labradorítica> piroxenos+olivino y minerales opacos (Martínez-Reyes, 1992). El gabro en ocasiones está emplazado a lo largo de fallas, ocupa un área de $c a .70 \mathrm{~km}^{2}$ y tiene un espesor que alcanza $100 \mathrm{~m}$. Su edad se ubica entre el Chattiano y el Serravalliano, por intrusionar a la Ignimbrita Cuatralba y estar cubierto por basaltos miocénicos correlacionables con el basalto El Cubilete (Vassallo-Morales et al., 2001).

Rocas volcánicas del Mioceno (Mba en Figura 2A). En este conjunto litológico se incluyen los basaltos y andesitas del Mioceno de entre 16 y 8 Ma: basalto El Cubilete (Martínez-Reyes 1992), andesita Mesa de Santiago (Quintero-Legorreta, 1992), basalto Mesa San José, andesita La Ordeña (Nieto-Samaniego et al., 1990) y andesita y basalto La Joya (Alaniz-Álvarez et al., 2001).

Martínez-Reyes (1992) documentó el basalto El Cubilete, que se encuentran a lo largo de la SG como lavas de basalto de olivino y andesita de augita. El basalto El Cubilete fue fechado en 13.5 Ma por Aguirre-Díaz et al. (1997) en su localidad tipo del Cerro del Cubilete. Estos basaltos se pueden correlacionar con las andesitas y basaltos que afloran en la Mesa del Obispo (Figura 2A). Quintero-Legorreta (1992) documenta la andesita Mesa de Santiago que aflora al noroeste de la SG, al sur de Comanja de Corona (Figura 2A). La describe como andesita de textura afanítica, constituida de cristales de andesina y piroxeno. Estas rocas se encuentran en contacto con el CVSG y sobreyace concordante a las ignimbritas del Rupeliano. Nieto-Samaniego et al. (2012) describieron la andesita La Ordeña, ubicada en la caldera La Ordeña (Figura 2A), como compuesta de derrames masivos de andesita y una mineralogía que consiste en plagioclasa y piroxeno inmersos en una mesostasis microcristalina. En esta área hay domos de composición andesítica que también están incluidos en esta unidad, su espesor es variable y se les estimó un máximo de 320 m. Cerca-Martínez et al. (2000) fecharon esta unidad obteniendo una edad de $14.3 \pm 0.5 \mathrm{Ma}$ (K-Ar en roca entera). Nieto-Samaniego et al. (2012) reportaron el basalto Mesa San José en los alrededores de la caldera La Ordeña, como derrames de lava de color gris de composición basáltica y andesítica, presentes en forma de mesetas; su espesor fue determinado por Nieto-Samaniego (1990) en $40 \mathrm{~m}$ y su edad ha sido reportada por varios autores, entre ellos Cerca-Martínez et al. (2000), quienes obtuvieron una edad de $12 \pm 0.3$ y $10.6 \pm 0.3 \mathrm{Ma}$ (K-Ar, roca entera). Alaniz-Álvarez et al. (2001) nombraron andesita y basalto La Joya a derrames y aparatos menores que afloran en las mesas ubicadas al NE del área de estudio.

\subsection{PRINGIPALES SISTEMAS DE FALLAS}

\subsubsection{SISTEMA FALLA DEL BAJÍO}

En el presente trabajo consideramos parte de este sistema al conjunto de fallas que forman un semigraben que se extiende desde León hasta Celaya, con el bloque hundido al SW y que limita las sierras de Guanajuato y Codornices (Figura 2A). Su carácter de semigraben está evidenciado por la ausencia de fallas mayores con echado contrario a la falla del Bajío, que limiten hacia el SW la cuenca de El Bajío. El Sistema Falla del Bajío se divide en dos segmentos: el primero se extiende desde Celaya hasta Salamanca y tiene dirección E-W con $45 \mathrm{~km}$ de longitud; el segundo segmento se extiende desde Salamanca hasta el norte de León, tiene rumbo NW-SE y una longitud de 100 km. El Sistema Falla del Bajío pierde su expresión morfológica en la intersección con el Graben de La Sauceda. El bloque levantado lo constituyen las sierras de Guanajuato y Codornices, mientras que el bloque hundido es la Cuenca de El Bajío, perteneciente a la FVTM (Alaniz-Álvarez et al., 2001; Botero-Santa et al., 2015; Nieto-Samaniego et al., 2005). El desplazamiento vertical total de este sistema de fallas se ha estimado en $850 \mathrm{~m}$ en las cercanías de León, considerando solamente el desplazamiento de unidades oligocénicas (Quintero-Legorreta, 1992). Sin embargo, si se le suma el espesor de $500 \mathrm{~m}$ de los sedimentos que rellenan 
la Cuenca de El Bajío (Hernández-Laloth, 1991), el rechazo vertical alcanza $1350 \mathrm{~m}$. El desplazamiento post-Mioceno se puede estimar en la zona de Silao, donde el basalto El Cubilete tiene un desplazamiento vertical de $500 \mathrm{~m}$.

Se han registrado tres episodios de actividad del Sistema Falla del Bajío. El primero es de edad eocénica y fue inferido a partir del basculamiento de las capas de los conglomerados Guanajuato y Duarte. El segundo episodio ocurrió en el Oligoceno, registrado por un pronunciado basculamiento de las ignimbritas del Rupeliano, así como por la posición horizontal de ignimbritas del Chattiano (Botero-Santa et al., 2015). El tercer episodio se manifiesta en el desplazamiento de las rocas del Mioceno (Alaniz-Álvarez et al., 2005; Botero-Santa et al., 2015).

\subsubsection{GRABEN VILLA DE REYES}

El graben Villa de Reyes es una fosa tectónica de edad Oligoceno, tiene una orientación NE en su parte sur y NNE en su parte norte, su longitud es de aproximadamente $200 \mathrm{~km}$, su ancho varía entre 10 y 20 km (Tristán-González, 1986; Nieto-Samaniego et al., 1999) y se han documentado desplazamientos verticales entre $250 \mathrm{~m}$ y 800 m (Ramos-Leal et al., 2007b; Tristán-González, 1986). La actividad del graben ocurrió simultáneamente con la actividad volcánica de la zona (Tristán-González, 1986). En el área de estudio está incluida solo el extremo sur del graben, donde se intersecta con la Sierra de Guanajuato (Figura 2A).

\subsubsection{FALLAS DEL DISTRITO MINERO DE GUANAJUATO}

Hay cuatro estructuras principales en el DMG: 1) La Veta Madre está formada por una falla principal de tipo normal, de rumbo NW-SE e inclinación al SW, y tiene una longitud reconocida de $16 \mathrm{~km}$, habiendo informes técnicos que le asignan una longitud de hasta 26 km (Echegoyén-Sánchez et al., 1970; Nieto-Samaniego et al., 2015). La Veta Madre tiene un desplazamiento al echado de 1400 m, medido en el Tiro Guanajuato de la Mina-Las
Torres (Gross, 1975). La última fase de activación de la Veta Madre ocurrió en el Rupeliano (Nieto-Samaniego et al., 2015). 2) La Falla La Leona es una falla normal de rumbo preferencial $\mathrm{N} 30^{\circ} \mathrm{W}$ inclinada al NE, tiene longitud de más de $5 \mathrm{~km}$ y un desplazamiento vertical cercano a $200 \mathrm{~m}$, el cual ocurrió antes de los $30 \mathrm{Ma}$ (Nieto-Samaniego et al., 2015). 3) La Falla El Cubo-Villalpando es de tipo normal con rumbo $\mathrm{N} 20^{\circ}-30^{\circ} \mathrm{W}$ e inclinación al SW y está formada por dos segmentos principales que en conjunto tienen una longitud de 6 km. El desplazamiento de la Falla El Cubo-Villalpando es de $200 \mathrm{~m}$ y su actividad fue posterior al depósito de la Riolita Chichíndaro. 4) La Falla Las Gachas es de tipo normal, con rumbo N20 $40^{\circ} \mathrm{W}$ e inclinación al SW; tiene una longitud de $7 \mathrm{~km}$ aproximadamente. El desplazamiento de la Falla Las Gachas se estimó de 350 m con base en los desniveles de los escarpes, y su última fase de activación fue posterior a los $30 \mathrm{Ma}$ (Nieto-Samaniego et al., 2015).

\subsubsection{GRABEN DE LA SAUCEDA}

Nieto-Samaniego (1990) documentó la presencia de un graben que es el límite suroriental de la Sierra de Guanajuato y el límite norte de la Sierra de Codornices. Se trata de una depresión topográfica de $250 \mathrm{~m}$ en promedio con una orientación $\mathrm{N} 75^{\circ} \mathrm{E}$ y dimensiones de $17 \mathrm{~km}$ de largo y $7.5 \mathrm{~km}$ de ancho (Figura 2A). El graben está definido por tres fallas normales principales: (1) la Falla Septentrional, cuyo rumbo es de $\mathrm{N} 65^{\circ} \mathrm{E}$ e inclinación al SE y constituye el límite SE del Distrito Minero Guanajuato; tiene $10 \mathrm{~km}$ de longitud aproximadamente y su desplazamiento es posiblemente mayor a 250 m. (2) La Falla Meridional y (3) la Falla La Gloria tienen una longitud aproximada de $17 \mathrm{~km}$ y se observan cortando fallas asociadas al Sistema Falla del Bajío. En conjunto, el desplazamiento vertical de las fallas Meridional y La Gloria es de $400 \mathrm{~m}$. La actividad principal del graben tuvo lugar en el Chattiano, después de los 30 Ma ya que los desplazamientos mayores se observan en rocas del Rupeliano y hubo desplazamientos menores en rocas del Chattiano. 


\section{Descripción de secciones}

\subsection{SECTOR NW DEL ÁREA DE ESTUDIO (SEGGIONES A-I)}

Este sector comprende parte de la Sierra de Guanajuato y parte del Graben de Villa de Reyes (GVR), e incluye las secciones A a I, todas ellas de rumbo general NE-SW viendo al NW (Figuras $2 \mathrm{~B}$ y 3). En el sector NW se puede observar un contraste geomorfológico importante, la parte SW tiene cotas cercanas a 1800 m s.n.m., en la zona que ocupa la cuenca continental denominada El Bajío; en contraste, en la parte elevada, que corresponde a la Sierra de Guanajuato, las cotas varían entre 1900 y 2850 m s.n.m. En este sector, las rocas del Jurásico-Cretácico afloran con cotas máximas de hasta 2700 m s.n.m., y en la cuenca El Bajío se interpreta, con base en la información disponible de pozos (Ramos-Leal et al., 2007a) y los espesores reportados de las unidades que las cubren, que se ubican en cotas inferiores a $1500 \mathrm{~m}$ s.n.m., según las secciones D, F y G.

Un rasgo distintivo de este sector es la presencia del Granito Comanja (GC), cuyo afloramiento es alargado con su eje mayor paralelo al Sistema Falla del Bajío y está emplazado en rocas del Jurásico-Cretácico. Cubriendo directamente al granito hay derrames de lava basáltica de edad Mioceno medio (sección I) y no se han reconocido unidades más jóvenes encima de dichas lavas. Se observa que la incisión máxima de los arroyos en el GC es

\section{SECTOR NOROESTE}
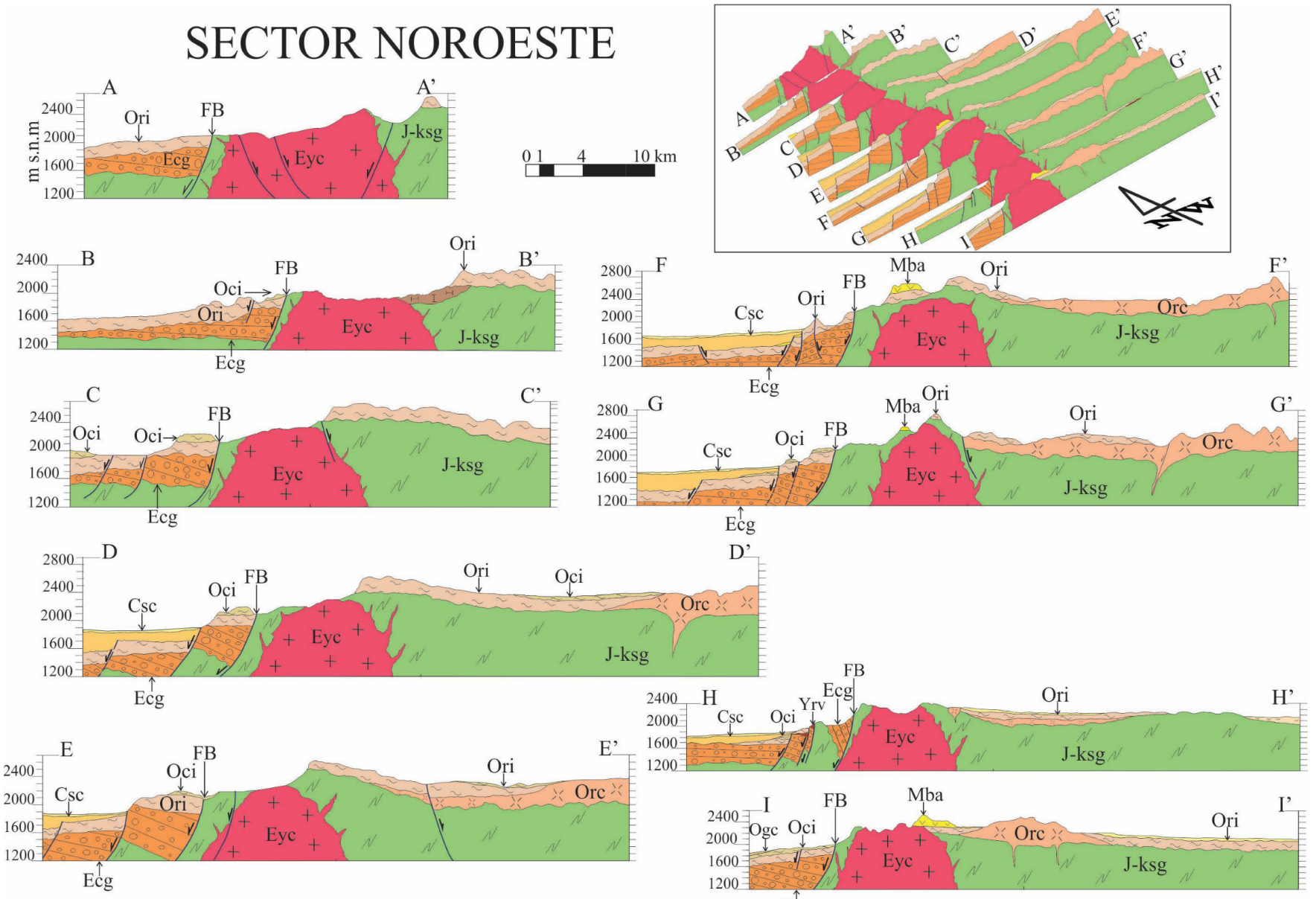

E $\begin{array}{r}1600 \\ 1200\end{array}$
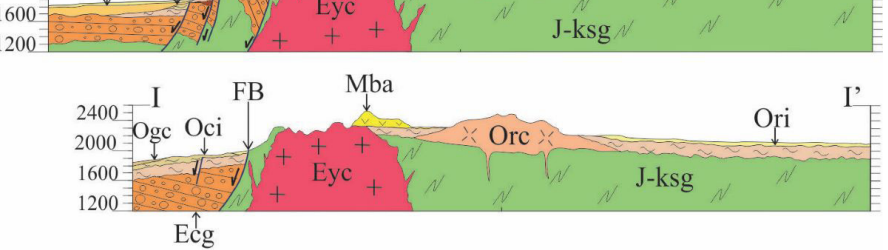

Figura 3 Secciones geológico-estructurales del Sector NW de A-A' a I-l' con imagen esquemática de ubicación de las secciones. La simbología de la estratigrafía corresponde al mapa geológico de la Figura 2; FB señala la falla principal del Sistema Falla del Bajío. 
de $c a .400 \mathrm{~m}$, esto se determinó por la diferencia de cotas sobre un mismo arroyo, desde la cúpula del intrusivo hasta la erosión más profunda en el contacto con las rocas del Jurásico-Cretácico. Si se considera que la exhumación del GG tuvo lugar a finales del Ypresiano (Ángeles-Moreno et al., 2017), las observaciones anteriores implican que en el Eoceno medio el granito ya había sido exhumado y permaneció expuesto hasta el Mioceno medio, en el que fue nuevamente sepultado por las lavas basálticas. Se infiere que el sector NW de la SG experimentó tres fases de erosión mayores: una al final del Ypresiano (Eoceno temprano) (exhumación del GC), la segunda durante el Oligoceno tardío-Mioceno temprano (erosión de la cubierta oligocénica) y la tercera del Mioceno medio al Cuaternario (erosión de la cubierta basáltica miocénica).

En este sector se interpreta que la discordancia, entre las rocas del Jurásico-Cretácico y los conglomerados eocénicos, se encuentra al alto de la falla del Bajío (Figura 3). En general los conglomerados presentan inclinaciones de $9^{\circ}$ a $13^{\circ}$ buzando hacia el noreste, pero en la sección $\mathrm{H}$ la inclinación de los estratos llega a ser hasta de $34^{\circ}$. Las rocas del Ypresiano se encuentran únicamente en el bloque del alto de la falla principal del Sistema Falla del Bajío (sección $\mathrm{H}$ ), yaciendo discordantemente sobre las rocas del Jurásico-Cretácico y siendo notable su ausencia hacia el bloque del bajo.

Los afloramientos de la Riolita Chichíndaro aumentan en extensión hacia el SE, la riolita descansa directamente sobre las rocas del Jurásico-Cretácico y subyace a las ignimbritas del Rupeliano. En El Bajío las ignimbritas del Rupeliano descansan discordantemente sobre el Conglomerado Duarte y subyacen discordantemente a las ignimbritas del Chattiano. Las capas de las ignimbritas rupelianas se encuentran basculadas $10^{\circ}-20^{\circ}$ al NE, mientras que las ignimbritas del Chattiano cubren a la Falla del Bajío (sección E) y sus capas están horizontales. En algunas localidades los basaltos del Mioceno descansan directamente sobre las rocas del Jurásico-Cretácico (sección $\mathrm{G}$ ), y en otras descansan sobre las rocas del Rupeliano (sección C, F y I).

La falla principal del Sistema Falla del Bajío (FB) tiene asociadas varias fallas sintéticas paralelas, que en conjunto forman el frente montañoso de la SG, separándola de la cuenca El Bajío (Figuras 2B y 3). Hacia el NE, la SG no está limitada por fallas, lo que se observa es que la cubierta de rocas del Rupeliano muestra un suave buzamiento, configurando así a la SG como un bloque basculado al NE.

\subsection{SEGTOR GENTRO DEL ÁREA DE ESTUDIO (SEGGIONES J-R)}

Este sector incluye parte de la Sierra de la Guanajuato, la mitad SE del GVR y la mitad NW del Graben de La Sauceda. En este sector se trazaron las secciones J a R (Figuras 2B y 4), todas ellas de rumbo general NE-SW viendo al NW. La zona de la cuenca El Bajío tiene elevaciones cercanas a 1700 m s.n.m., mientras que en la parte que corresponde a la SG las cotas varían de 1800 a 2800 m s.n.m. Por otra parte, las cotas máximas de los afloramientos de rocas del Jurásico-Cretácico llegan hasta 2500 m s.n.m (sección M) y en El Bajío se interpreta que esas rocas están ubicadas en cotas inferiores a 1400 m s.n.m. (sección J).

En este sector, el Conglomerado Guanajuato cubre discordantemente las rocas del Jurásico-Cretácico y subyace a las rocas del Ypresiano; sin embargo, en algunos lugares está cubierto discordantemente por los basaltos del Mioceno (secciones Ñ y O). El Conglomerado presenta espesores más grandes y sus afloramientos son más extensos que en el sector NW; comúnmente sus estratos buzan entre $20^{\circ}$ y $60^{\circ}$ al NE. En la parte SE de este sector, las rocas del Rupeliano cubren en discordancia las rocas del Jurásico-Cretácico y subyacen a los basaltos del Mioceno (secciones L, M, P y Q y en la parte centro del sector, se observa a las rocas del Rupeliano descansando sobre los conglomerados eocénicos (secciones $\mathrm{N}$ a $\mathrm{P}$ y $\mathrm{R}$ ). Hay lugares donde el basalto del Mioceno descansa directamente sobre las rocas 
del Jurásico-Cretácico (sección K), esta relación se observa en los tres sectores, lo que indica una etapa erosiva pre-Mioceno medio importante.

Las fallas en este sector se concentran en el área del DMG, cuyas estructuras son: la Veta Madre, Falla Cubo-Villalpando, Falla Las Gachas y la Falla La Leona. La falla más grande en longitud y desplazamiento es la Veta Madre. En las secciones de la Figura 4 se aprecia el sistema de horts y medios grábenes descritos por Nieto-Samaniego $e t$ al. (2015). Entre las fallas La Leona y El Cubo-Villalpando se forma el graben del Cubo (secciones O, P y Q y el bloque hundido de la Falla Veta Madre forma el graben Veta Madre (secciones $\mathrm{O}$, P y Q.

\subsection{SEGTOR SE DEL ÁREA DE ESTUDIO (SEGGIONES}

S-Z)

Este sector abarca la mitad SE del graben de La Sauceda hasta el extremo SE del área de estudio, e incluye las secciones $\mathrm{S}$ a Z (Figura 2B y 5), todas ellas de rumbo general NE-SW viendo al NW. En este sector el desnivel topográfico va de 1700 a 2400 m s.n.m. y son pocos los afloramientos de rocas del Jurásico-Cretácico. En las secciones S a X las rocas del Jurásico-Cretácico no afloran, mientras que en las secciones $\mathrm{Y}$ y Z se encuentran pequeños afloramientos de ellas. La cota máxima de los afloramientos de rocas del Jurásico-Cretácico es de 2000 m s.n.m. (sección Y-Y’) y la cota mínima interpretada en el subsuelo es de 1300 m s.n.m.
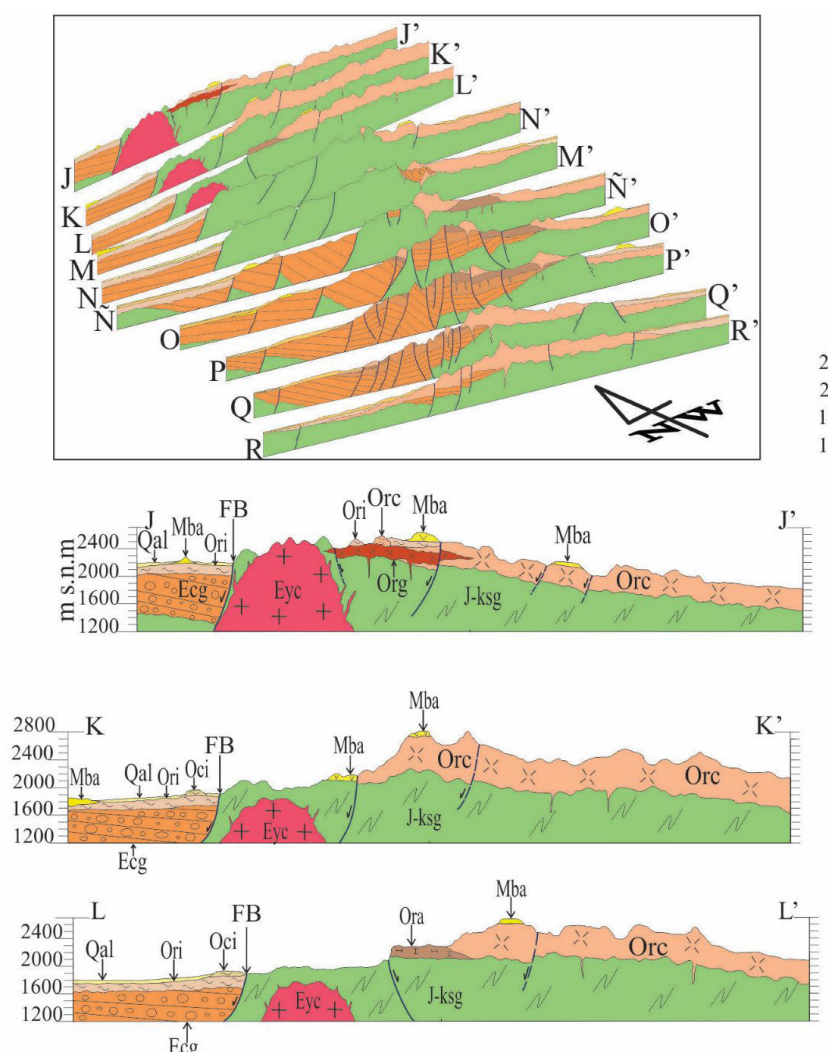

Ecg
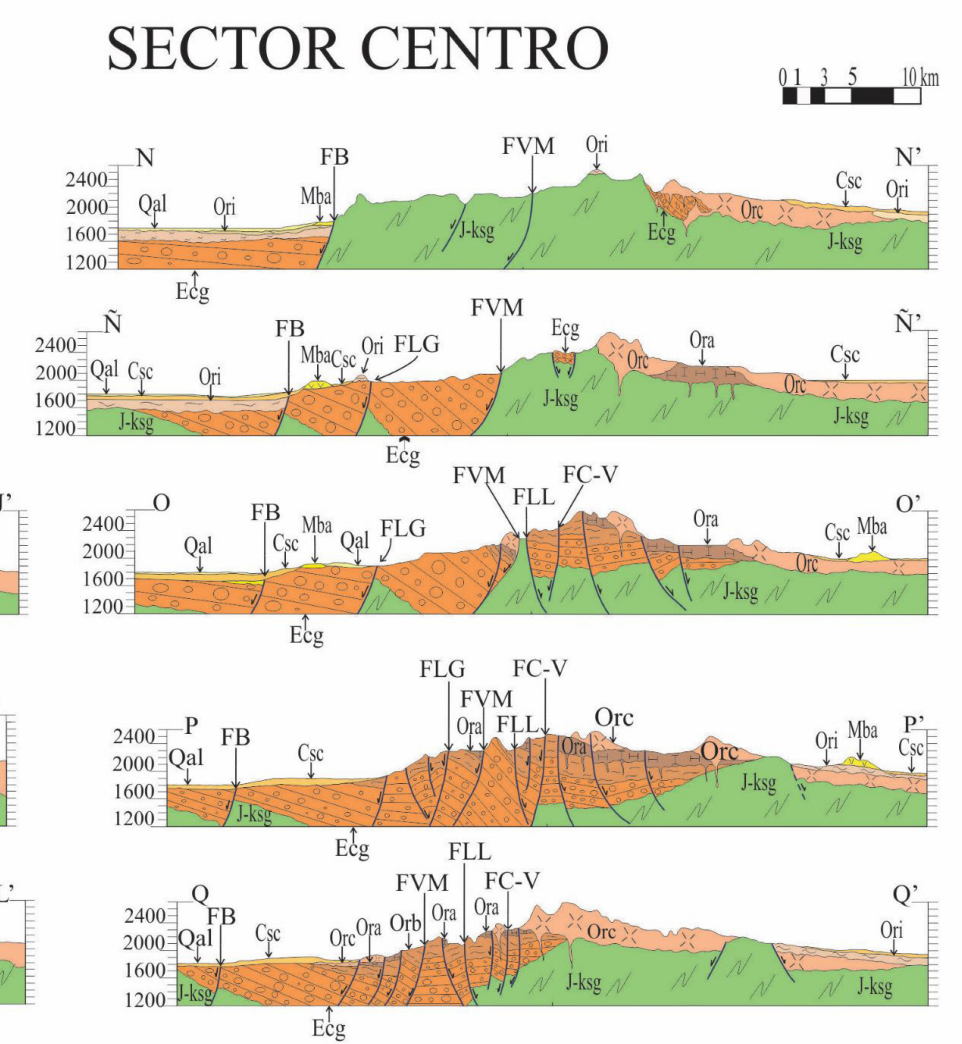

Ecg

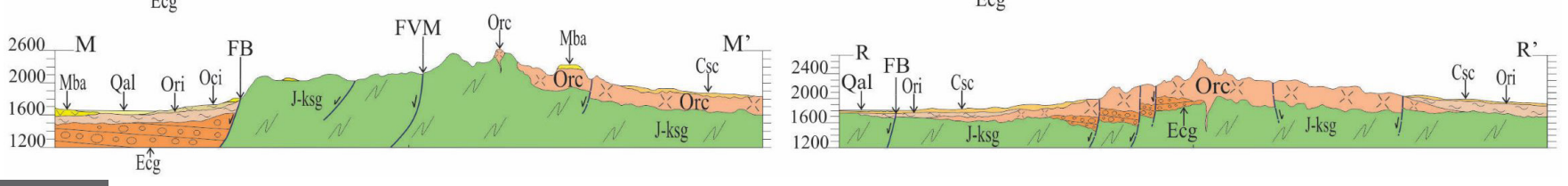

Figura 4 Secciones geológico-estructurales del Sector Centro del área de estudio de J-J' a R-R' con imagen esquemática de ubicación de las secciones. La simbología de la estratigrafía corresponde al mapa geológico de la Figura 2; FB señala la falla principal del Sistema Falla del Bajío, FLG: Falla Las Gachas, FVM: Falla Veta Madre, FLL: Falla la Leona, FC-V: Falla el Cubo Villalpando. 


\section{SECTOR SURESTE}
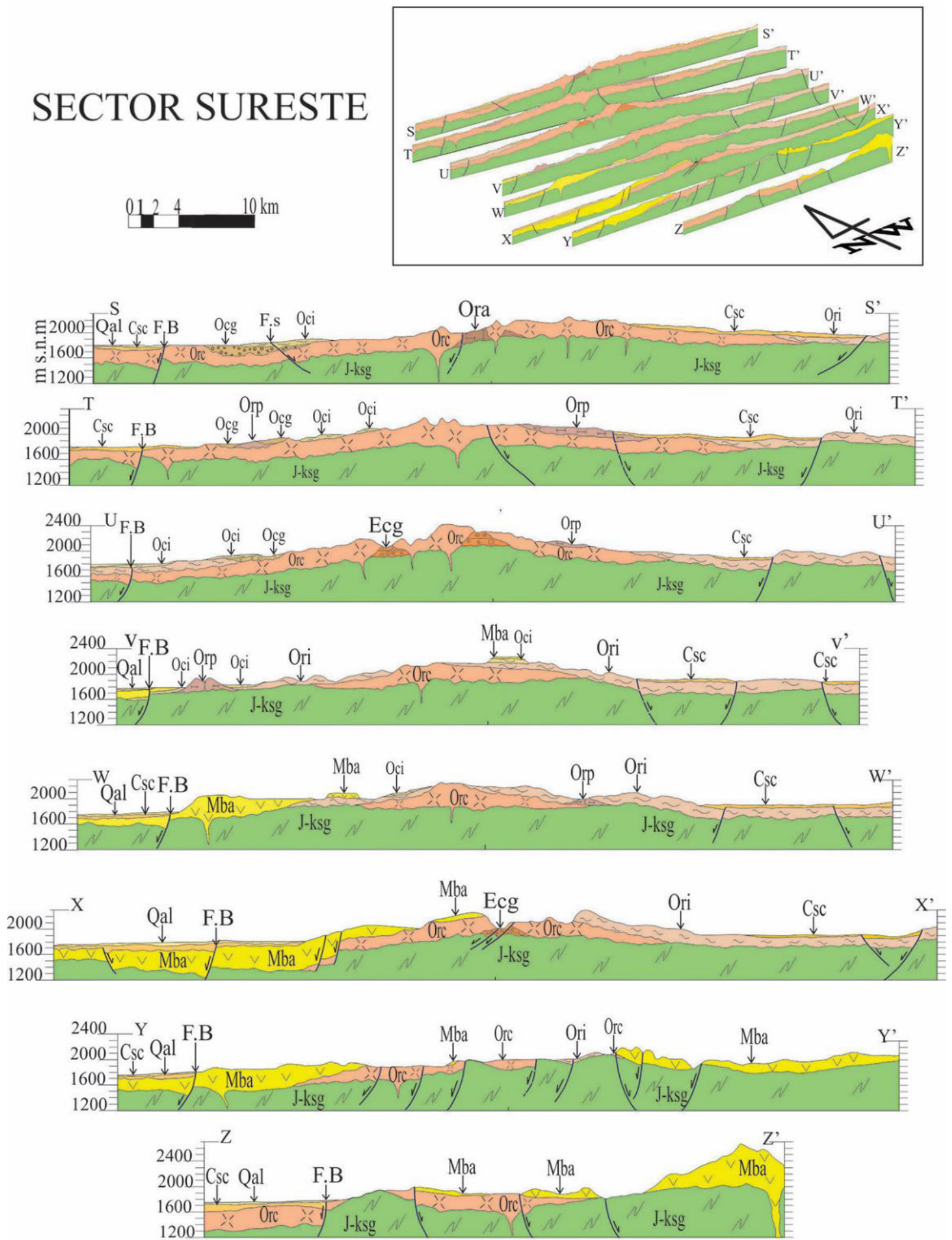

Figura 5 Secciones geológico-estructurales del sector NW del área de estudio S-S'-Z-Z' con imagen esquemática de las secciones. La simbología de la estratigrafía corresponde al mapa geológico de la Figura 2; FB señala la falla principal del Sistema Falla del Bajío. 
(sección X-X'). Los conglomerados eocénicos son escasos (secciones $\mathrm{U}$ y $\mathrm{X}$ ) y presentan echados de hasta $30^{\circ}$. Dada la escasez de conglomerados eocénicos, la gran discordancia que descansa sobe las rocas del Jurásico-Cretácico representa hiatos mayores en este sector; en las secciones $\mathrm{V}$ a $\mathrm{Z}$ los basaltos del Mioceno descansan directamente sobre las rocas del Jurásico-Cretácico y en las secciones $\mathrm{Y}$ y $\mathrm{Z}$ esa discordancia separa a las rocas del Jurásico-Cretácico de las rocas del Rupeliano.

Las estructuras principales de este sector son las fallas del graben de La Suceda, la Falla de San Miguel de Allende, que forma un medio graben orientado N-S, la Falla del Bajío, con una traza no tan evidente en comparación con los sectores NW y Centro, y la falla de la caldera La Ordeña, que corta rocas del Mioceno.

\section{Discusión}

\subsection{LEVANTAMIENTO DE LA SIERRA DE GUANAJUATO}

La fuerte erosión y el levantamiento de la Sierra de Guanajuato con respecto a los valles adyacentes están documentados por la presencia de remanentes de depósitos conglomeráticos en los costados de la sierra (Nieto-Samaniego, 1992; Martínez-Reyes, 1992). Dichos depósitos corresponden a los conglomerados Duarte y Guanajuato, que se concentran en los sectores NW y Centro del área de estudio. En el Sector NW afloran espesores de hasta 1700 m de conglomerado (Miranda-Avilés et al., 2016), mientras que en el Sector Centro afloran espesores de 1200 m (sección O). En contraste, en el Sector SE los afloramientos de conglomerado son escasos y aunque en algunos no se ha observado su base, los espesores expuestos son menores de $200 \mathrm{~m}$ (sección U).

El levantamiento de la Sierra de Guanajuato es desigual en sus diferentes sectores. El Sector NW está más levantado con respecto a los sectores Centro y SE. Si se consideran las alturas máxima y mínima que tienen las rocas del Jurásico-Cretácico, se puede inferir un levantamiento diferencial a lo largo de la SG. En el sector NW el desnivel promedio de las rocas del Jurásico-Cretácico es de $\sim 1375$ m medido en las secciones D a G (Figura 3), seleccionadas por mayor cantidad de datos; por su parte, en el Sector Centro es de $\sim 1275 \mathrm{~m}$ en las secciones M y N (Figura 4) y en el Sector SE es de $\sim 450 \mathrm{~m}$ en las secciones $\mathrm{S}$ y $\mathrm{T}$ (Figura 4).

Otra evidencia que apoya el mayor levantamiento del Sector NW es la exposición del Granito Comanja a elevaciones de 2700 m s.n.m., cuya exhumación tuvo lugar en el Eoceno. Dicha exhumación ocurrió durante el depósito del Conglomerado Duarte, ya que en el Conglomerado hay clastos de granito con abundante turmalina y feldespatos potásicos rosados. Esos clastos son muy semejantes al Granito Comanja, ya que las otras rocas plutónicas del área de estudio no contienen turmalina. El GC fue sepultado por basaltos de edad miocénica (Tortoniano), lo que dio lugar a una segunda fase de levantamiento y erosión, ocurrida a partir del Tortoniano hasta el presente, en la cual la incisión de los arroyos en el granito alcanzó hasta $400 \mathrm{~m}$.

La Riolita Chichíndaro está distribuida en la mitad NE de la SG y en el graben de La Sauceda (Figuras 3, 4 y 5), extendiéndose ampliamente hacia el oriente de la SG, fuera del área de estudio. El emplazamiento de la Riolita Chichíndaro fue controlado por extensión, y se localiza a lo largo de fallas que dejan diques, domos y derrames riolíticos alineados (Nieto-Samaniego et al., 2005; Orozco-Esquivel et al., 2002). Se puede interpretar que a mediados del Rupeliano (edad de la Riolita Chichíndaro, ca. 30.5 Ma: Nieto-Samaniego, 1996; Nieto-Samaniego et al., 2015) ocurrió actividad de fallas normales y vulcanismo efusivo a lo largo de la parte oriente de la SG. Al mismo tiempo, hacia la parte poniente de la sierra (bloque del alto de la falla principal del Sistema Falla del Bajío) ocurrió actividad de fallas normales, evidenciado por las ignimbritas del Rupeliano basculadas hasta $35^{\circ} \mathrm{y}$ cubiertas por ignimbritas del Chattiano que están horizontales (Botero-Santa et al., 2015). La menor cantidad de fallas normales oligocénicas a lo largo del eje y mitad NE de la Sierra de Guanajuato, 
sugiere que buena parte de la deformación se acomodó por el emplazamiento de grandes volúmenes de rocas volcánicas efusivas (diques y domos riolíticos), lo que contrasta con el frente SW, donde el volcanismo efusivo estuvo ausente.

En el sector NW de la SG los basaltos del Mioceno se encuentran aflorando, mientras que en la cuenca El Bajío interpretamos que se encuentran cubiertos por los rellenos de la fosa. Los desplazamientos de los basaltos del Mioceno en el sector NW son como mínimo de 950 m (Figura 3, sección F), mientras que en el sector Centro los basaltos del cerro El Cubilete llegan a tener desplazamientos de más de 500 m (Nieto-Samaniego et al., 2005).

El desplazamiento vertical del Sistema de Fallas El Bajío en el sector SE es de $350 \mathrm{~m}$ a 500 m (Nieto-Samaniego et al., 2015) y los espesores de los rellenos de la fosa de Celaya son de $250 \mathrm{~m}$. A esa profundidad se encuentran basaltos presumiblemente del Pleistoceno (Trujillo-Candelaria, 1985)

Las observaciones anteriores indican que la SG tuvo tres fases mayores de levantamiento y erosión, la primera de ellas en el Eoceno tardío (Lutetiano al Priaboniano), la segunda en el Oligoceno tardío (Chattiano) y la tercera, con la cual adquirió su configuración morfológica actual, ocurrió durante el Mioceno tardío-Cuaternario, pues su levantamiento relativo con respecto a la cuenca El Bajío ocurrió después del Serravaliano. De las tres fases el levantamiento fue de mayor magnitud en los sectores NW y Centro. La tercera fase tuvo etapas sucesivas que le imprimieron la configuración escalonada que se observa actualmente en el frente SW de la sierra.

\subsection{VULCANISMO EOCÉNICO}

Las rocas volcánicas de edad eocénica fueron reportadas por Aranda-Gómez y McDowell (1998), refiriéndose a un derrame de basalto intercalado con el Conglomerado Guanajuato

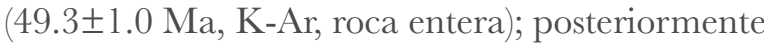
Olmos-Moya (2016) fechó derrames de riolita

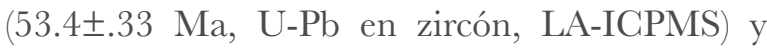
Ruiz-González (2015) fechó una ignimbrita en
48.82 \pm 0.97 Ma. (U-Pb en zircón, LA-ICPMS) intercalada en el Conglomerado Duarte. Estos afloramientos de rocas eocénicas, que son escasos (Sección H en Figura 3), pueden ser remanentes de una cubierta más extensa, ya erosionada, que cubría amplias zonas de la Sierra de Guanajuato.

Esto lo inferimos a partir de las siguientes observaciones: a) En la SG ocurrió una intensa erosión en el Eoceno; b) Los conglomerados Guanajuato y Duarte contienen numerosos clastos de rocas volcánicas ácidas (riolita e ignimbrita) (Edwards, 1955; Miranda-Avilés et al., 2016). En esos clastos no se observan evidencias de metamorfismo ni deformación y no están alterados, su apariencia es muy semejante a las riolitas de edad oligocénica que afloran en los alrededores, no obstante, no se han reconocido afloramientos de la roca fuente. Por todo ello consideramos más probable que dichos clastos sean de edad eocénica, ya que están contenidos en conglomerados eocénicos que descansan sobre las rocas marinas del Jurásico-Cretácico y son cubiertos por rocas volcánicas oligocénicas. Considérese además que el vulcanismo eocénico formó un extenso arco volcánico en todo el Occidente de México (Aguirre-Díaz y McDowell, 1991; Nieto-Samaniego et al., 2005).

\section{Conclusiones}

- El área de estudio (sierras de Guanajuato y Codornices) experimentó tres grandes fases de levantamiento-exhumación, una de ellas tuvo lugar en el Eoceno temprano-medio, la segunda en el Oligoceno y la tercera en el Mioceno.

- La actividad del Oligoceno y Mioceno de las fallas normales se dio en fases sucesivas, con las zonas activas migrando hacia la cuenca, eso le imprimió la configuración escalonada al frente SW de las sierras de Guanajuato y Codornices.

- El área de estudio adquirió su configuración actual durante el levantamiento-exhumación del Mioceno. El levantamiento relativo con respecto a la cuenca El Bajío se dio a partir del Serravaliano, debido a la actividad de fallas normales 
localizadas a lo largo del frente SW de las sierras de Guanajuato y Codornices.

- A todo lo largo del frente NE del área de estudio las fallas normales son escasas y no se aprecia un frente montañoso escarpado y bien definido. Lo que se observa es que las unidades volcánicas se inclinan suavemente hacia el NE, imprimiéndole a toda el área la forma de un bloque basculado hacia el NE, y formando también el bloque levantado de un medio graben.

- A lo largo de la historia del levantamiento de la Sierra de Guanajuato, las magnitudes de los levantamientos fueron siempre mayores en los sectores NW y Centro.

- La actividad volcánica del Rupeliano presenta una diferencia sustancial en su distribución: a lo largo del frente SW se depositaron rocas piroclásticas (flujos y depósitos de caída), mientras que a lo largo del frente NE se emplazaron grandes volúmenes de rocas volcánicas efusivas (diques, domos y derrames riolíticos).

- Las rocas volcánicas del Eoceno se encuentran únicamente en el sector NW como remanentes de una cubierta, ya erosionada, que posiblemente cubría buena parte de la Sierra de Guanajuato, y cuyo registro se encuentra en los clastos de rocas volcánicas de los conglomerados Duarte y Guanajuato.

\section{Agradecimientos}

Este manuscrito forma parte del proyecto PAPIIT-UNAM - IN 105417. Agradecemos a Margarito Tristán y Michelangelo Martini por su cuidadosa revisión y sugerencias, las cuales mejoraron sustancialmente este trabajo.

\section{Referencias}

Aguirre-Díaz, G.J., McDowell, F., 1991, The volcanic section at Nazas, Durango, Mexico, the possibility of widespread Eocene volcanism in the Sierra Madre Occidental: Journal of Geophysical Research, 96 (B8), 13373-13388. https:// doi.org/10.1029/91jb00245
Aguirre-Díaz, G.J., Nelson, S.A., Ferrari, L., López-Martínez, M., 1997, Ignimbrites of the central Mexican Volcanic Belt, Amealco and Huichapan Calderas (QuerétaroHidalgo), en Aguirre-Díaz, G. J., ArandaGómez, J.J., Carrasco-Núñez, G., Ferrari, L. (eds.), Magmatism and tectonics of central and northwestern Mexico: A selection of the 1997 IAVCEI General Assembly excursions: México, Universidad Nacional Autónoma de México, Instituto de Geología, Excursión 1, $1-39$.

Alaniz-Álvarez, S.A., Nieto-Samaniego, Á.F., Reyes-Zaragoza, M.A., Orozco-Esquivel, M.T., Ojeda-García, A.C., Vasallo, L.F., 2001, Estratigrafía y deformación extensional en la región San Miguel de Allende-Querétaro, México: Revista Mexicana de Ciencias Geológicas, 18(2), 129-148.

Alaniz-Álvarez, S.A., Nieto-Samaniego, Á.F., 2005, El sistema de fallas Taxco-San Miguel de Allende y la Faja Volcánica Transmexicana, dos fronteras tectónicas del centro de México activas durante el Cenozoico: Boletín de la Sociedad Geológica Mexicana, 57(1), 65-82. https://doi. org/10.18268/bsgm2005v57n1a4

Alvarado-Méndez, H., López-Ojeda, J.A., Caballero-Martínez, J.A., 1997a, Carta Geológico-Minera Guanajuato F14C43 1:50000: Servicio Geológico Mexicano, Secretaría de Economía, 1 mapa con texto explicativo.

Alvarado-Méndez, H., Sánchez-Garrido, E., Pérez-Vargas, M., Caballero-Martínez, J.A., 1997b, Carta Geológico-Minera Guanajuato F14-7 Gto., S. L. P., Jal., Zac., Ags. y Qro., Escala 1:250000: Servicio Geológico Mexicano, Secretaría de Economía, 1 mapa con texto explicativo.

Ángeles-Moreno, E., Nieto-Samaniego, Á.F., Ruiz-González, FJ., Levresse, G., AlanizÁlvarez, S.A., Olmos-Moya M.J.P., Xu, S., Miranda-Avilés, R., 2017, The transition between shortening and extensional regimes in central Mexico recorded in the tourmaline veins of the Comanja Granite: Journal of South American Earth Sciences, 73(1), 65-77. https://doi.org/10.1016/j. jsames.2016.12.004 
Aranda-Gómez, J.J., McDowell, F., 1998, Paleogene extension in the southern Basin and Range province of Mexico: syndepositional tilting of Eocene red beds and Oligocene volcanic rocks in the Guanajuato Mining District: International Geology Review, 40 (2), 116-134. https:// doi.org/10.1080/00206819809465201

Botero-Santa, P.A., Alaniz-Álvarez, S.A., NietoSamaniego, Á.F., López-Martínez, M., Levresse, G., Xu, S., Ortega-Obregón, C., 2015, Origen y desarrollo de la cuenca El Bajío en el sector central de la Faja Volcánica Trans-mexicana: Revista Mexicana de Ciencias Geológicas, 32(1), 84-98.

Botsford, G.W., 1909, The Zacatecas District and its relations to Guanajuato and others camps: The Enginneering and Mining Journal, 87(1), 1227-1228.

Cerca-Martínez, L.M., Aguirre-Díaz., G., LópezMartínez, M., 2000, The geologic evolution of the southern Sierra de Guanajuato, Mexico: A documented example of the transition from the Sierra Madre Occidental to the Mexican Volcanic Belt: International Geology Review, 42 (2), 131-151. https:// doi.org/10.1080/00206810009465073

Davis,J.B., Glark, K., Randall,J.A., 2009, Relación de una caldera con la mineralización en el distrito minero de Guanajuato, en Clark, K.F., Salas Piza, G.A., Cubillas Estrada, R. (eds.), Geología Económica de México, A.C., México, Servicio Geológico Mexicano, 584-635.

Echegoyén-Sánchez, J., Romero-Martínez, S., Velázquez-Silva, S., 1970, Geología y yacimientos minerales de la parte central del Distrito Minero de Guanajuato: Guanajuato, Gto., México, Consejo de Recursos Naturales No Renovables, Informe técnico, 47 p.

Echegoyén-Sánchez, J., Cantero Pérez, E., Guerrero Álvarez, H., Calixto, J.M., 1975, Estudio geológico preliminar de la zona de Arperos, Gto. a Comanja de Corona, Jal.: Guanajuato, México, Consejo de Recursos Naturales no Renovables, informe interno, residencia Guanajuato, 14 p.
Edwards, J. D., 1955, Studies of some early tertiary red conglomerates of central Mexico: United States Geological Survey, Professional Paper 264-H, 184 p.

Ferrari, L., Valencia-Moreno, M., Bryan, S., 2005, Magmatismo y tectónica en la Sierra Madre Occidental y su relación con la evolución de la margen occidental de Norteamérica: Boletín de la Sociedad Geológica Mexicana, 57(3), 343-378. http://dx.doi.org/10.18268/ BSGM2005v57n3a5

Gross, W.H., 1975, New ore discovery and source of silver-gold veins, Guanajuato, Mexico: Economic Geology, 70(7), 1175-1189. https://doi.org/10.2113/ gsecongeo.70.7.1175

Hernández-Laloth, N., 1991, Modelo conceptual de funcionamiento hidrodinámico del sistema acuífero del valle de León, Guanajuato: México: Universidad Nacional Autónoma de México, Facultad de Ingeniería, tesis, 129 p.

INEGI (Instituto Nacional de Estadística, Geografía e Informática), 2015, Continuo de Elevaciones Mexicano 3.0 F14-7 y F14-10, acceso libre en: http://www.inegi.org.mx/ geo/contenidos/datosrelieve/continental/ Descarga.aspx

Martínez-Reyes, J., 1992, Mapa geológico de la Sierra de Guanajuato con resumen de la geología de la Sierra de Guanajuato: Universidad Nacional Autónoma de México, Instituto de Geología, Cartas Geológicas y Mineras, 8, 1 mapa con resumen de la geología.

Martini, M., Solari, L., Centeno-García, E., 2011, Sandstone provenance of Arperos Basin (Sierra de Guanajuato, Central Mexico): Late Jurassic-Early Cretaceous back arc spreading as the foundation of the Guerrero terrane: The Journal of Geology, 119(6), 597-617. https://doi.org/10.1086/661989

Miranda-Avilés, R., Puy-Alquiza, M.J., Omaña, L., Loza-Aguirre, I., 2016, Los depósitos clásticos pos-Laramide de la Sierra de Guanajuato: Implicaciones de su composición en la evolución tectonosedimentaria y paleogeográfica: Estudios Geológicos, 72(2), e058. http://dx.doi. org/10.3989/egeol.42480.417 
Nieto-Samaniego, Á.F., 1990, Fallamiento y estratigrafía cenozoica en la porción sudoriental de la Sierra de Guanajuato: Revista del Instituto de Geología, 9(2), 146-155.

Nieto-Samaniego, Á.F., Macías-Romo, C., AlanizÁlvarez, S.A., 1996, Nuevas edades isotópicas de la cubierta volcánica cenozoica de la parte meridional de la Mesa Central, México: Revista Mexicana de Ciencias Geológicas, 13(1), 117-122.

Nieto-Samaniego, Á.F., Ferrari, L., Alaniz-Álvarez, S.A., Labarthe-Hernández, G., RosasElguera, J., 1999, Variation of Cenozoic extension and volcanism across the southern Sierra Madre Occidental volcanic province, Mexico: Geological Society of America Bulletin, 111(3), 347-363. https://doi. org/10.1130/0016-7606(1999)111<0347:vo ceav>2.3.co;2

Nieto-Samaniego, Á.F., Alaniz-Álvarez, S.A., Camprubí-Cano, A., 2005, La Mesa Central de México: Estratigrafia, estructura y evolución tectónica cenozoica: Boletín de la Sociedad Geológica Mexicana, 53(3), 285-318. https://doi.org/10.18268/ bsgm2005v57n3a3

Nieto-Samaniego, Á.F., Ojeda-García, Á.C., Alaniz-Álvarez, S.A., Xu, S., 2012, Geología de la región de Salamanca, Guanajuato, México: Boletín de la Sociedad Geológica Mexicana, 64(3), 411-425. https://doi. org/10.18268/bsgm2012v64n3a10

Nieto-Samaniego, Á.F., Báez-López,J.A., Levresse, G., Alaniz-Álvarez, S.A., Ortega-Obregón, C., López-Martínez, M., Noguez-Alcántara, B., Solé-Viñas, J., 2015, New stratigraphic, geochronological, and structural data from the southern Guanajuato Mining District, Mexico: implications for the caldera hypothesis: International Geology Review, 58(2), 246-262. https://doi.org/10.1080/00 206814.2015.1072745

Olmos-Moya, M.J.P., 2016, Estratigrafía y estructuras cenozoicas del frente suroeste de la Sierra de Guanajuato: Universidad de Guanajuato, Departamento de Minas, Metalurgia y Geología, tesis de licenciatura, 113 p., inédita.
Orozco-Esquivel, M.T., Nieto-Samaniego, Á.F., Alaniz-Álvarez, S.A., 2002, Origin of rhyolitic lavas in the Mesa Central, Mexico, by crustal melting related to extension: Journal of Volcanology and Geothermal Research, 118 (1-2), 37-56. https://doi. org/10.1016/s0377-0273(02)00249-4

Ortega Gutiérrez, F., Mitre Salazar, L.M., Roldán Quintana, J., Aranda Gómez, J.J., Morán Zenteno, D.J., Alaniz Álvarez, S.A., Nieto Samaniego, Á.F., 1992, Carta geológica de la República Mexicana, quinta edición, Escala 1:2 000 000: México, Universidad Nacional Autónoma de México, Instituto de Geología; Secretaría de Energía, Minas e Industria Paraestatal, Consejo de Recursos Minerales, 1 mapa.

Ortiz-Hernández, L.E., Chiodi, M., Lapierre, H., Monod, O., Calvet, P., 1990, El arco intraoceánico alóctono (Cretácico Inferior) de Guanajuato- características petrográficas, geoquímicas, estructurales e isotópicas del complejo filioniano y de las lavas basálticas asociadas; implicaciones geodinámicas: Revista Mexicana de Ciencias Geológicas, 9(2), 126-145.

Ortiz-Hernández, L.E., Acevedo-Sandoval, O.A., Flores-Castro, K., 2003, Early Cretaceous intraplate seamounts from Guanajuato, central México: geochemical and mineralogical data: Revista Mexicana de Ciencias Geológicas 20(1), 27-40.

Pérez-Flores, E., Mauvois-Guitteaud, R., Menguelle-López, J., Moreno-Vázquez, J.L., Soto-Araiza, R.G., López-Ojeda, J.A., 1999, Carta Geológico-Minera Guanajuato F1410 Qro., Gto., Mich, Jal. y Edo Méx., Escala 1:250000: Servicio Geológico Mexicano, Secretaría de Economía, 1 mapa con texto explicativo.

QGIS Development Team, 2015, QGIS geographic information system. Open Source geospatial foundation project, disponible en: https://qgis.org/es/site/ 
Quintero-Legorreta, O., 1992, Geología de la región de Comanja, estados de Guanajuato y Jalisco: Revista del Instituto de Geología, 10(1), 6-25.

Ramos-Leal, J.A., Durazo, J., González-Morán, T., Juárez-Sánchez, F., Cortés-Silva, A., Johannesson, K.H., 2007a, Evidencias hidrogeoquímicas de mezclas de flujos regionales en el acuífero de La Muralla, Guanajuato: Revista Mexicana de Ciencias Geológicas, 25(3), 494-516.

Ramos-Leal, J.A., López-Loera, H., MartínezRuiz, V.J., Aranda-Gómez, J.J., 2007b, Sucesión de eventos y geometría de la parte central del acuífero del graben de Villa de Reyes (San Luis Potosí, México) inferida a partir de datos geoeléctricos: Revista Mexicana de Ciencias Geológicas, 24(1), 31-46.

Ruiz-González, F., 2015, Estudio de las vetas de turmalina que registran la historia de exhumación del Granito Comanja, Sierra de Guanajuato, México: Universidad Nacional Autónoma de México, Posgrado en Ciencias de la Tierra, tesis de maestría, 155 p.
Tristán-González, M., 1986, Estratigrafía y Tectónica del Graben de Villa de Reyes en los Estados de San Luis Potosí y Guanajuato, México: México, Universidad Autónoma de San Luis Potosí, Instituto Geología, Folleto Técnico 107, 54 p.

Trujillo-Candelaria, J.A., 1985, Origen del fallamiento, en Flores-Núñez, J., (ed.), Fallamiento de terrenos en Celaya: Celaya, Sociedad Mexicana de Mecánica de Suelos, 3-9.

Vassallo-Morales, L.F., Flores, L., Lazcano, L.M, Hernández, G., Solorio, G., Maples, M., Girón, P., Garduño, C., 2001, El gabro de Arperos y su aportación de Cr-Ni a la subcuenca del río Silao, Guanajuato, México: Ingeniería Hidráulica en México, 16(1), 63-71.

Wandke, A., Martínez, J., 1928, The Guanajuato Mining District, Guanajuato, Mexico: Economic Geology, 23(1), 1-44. https://doi. org/10.2113/gsecongeo.23.1.1 